\title{
Feasibility Assessment of an Innovative Isolation Bearing System with Shape Memory Alloys
}

\author{
GABRIELE ATTANASI ${ }^{1}$, FERDINANDO AURICCHIO ${ }^{2}$, \\ and GREGORY L. FENVES ${ }^{3}$ \\ ${ }^{1}$ ROSE School, IUSS Pavia, Pavia, Italy \\ ${ }^{2}$ Dipartimento di Meccanica Strutturale, Università degli Studi di Pavia, Pavia, \\ Italy \\ ${ }^{3}$ Department of Civil and Environmental Engineering, University of California, \\ Berkeley, California, USA
}

\begin{abstract}
The objective of this work is to investigate the feasibility of a new seismic isolation device concept based on the superelastic effect given by shape memory alloys. Seismic isolation is one of the most effective options for passive protection of structure, which modifies the global response and improves performances, in particular regularizing the structural response, shifting the fundamental period of vibration, and increasing the global energy dissipation. Shape memory alloys (SMAs) are characterized by unique mechanical properties due to a solid-solid transformation between phases of the alloy. They show high strength and strain capacity, high resistance to corrosion and to fatigue. Regarding the stress-strain constitutive law, the nonlinear hysteresis due to the superelastic effect, that for particular range of temperature can be described like a flag shaped relation, avoids residual deformation, provides some hysteretic energy dissipation and limits the maximum transmitted force. An isolation bearing system based on a SMA superelastic effect is intended to provide the nonlinear characteristics of yielding devices, limiting the induced seismic force and providing additional damping characteristics, together with recentering properties to reduce or eliminate the cumulative damage. Flag-shape hysteresis is characterized by much less energy dissipation with respect to other isolation device technology force-displacement relations, therefore its effectiveness has to be investigated. In this work the dynamic response of the proposed innovative SMA isolation devices has been compared with equivalent traditional bearing response through dynamic time history analyses. Results show that force and displacement demands in the two systems are quite similar for medium to high flag-shape dissipation capability range.
\end{abstract}

Keywords Seismic Isolation; Shape Memory Alloys; Superelastic Effect

\section{Introduction}

Major developments have occurred in the last years on advanced material properties. The term advanced in the civil structural context refers to a capability to increase the structural performance and safety and the building designs lifetime and its serviceability with respect to traditional materials. A key aspect to move towards the improved structural technology is the development of advanced materials and its integration in innovative structural systems to provide improved performance. An example of smart materials is Shape Memory Alloys, which have unique properties, including Young's modulus-temperature relations, shape memory effects, superelastic effects, and high

Address correspondence to Gabriele Attanasi, European School for Advanced Studies in Reduction of Seismic Risk (ROSE School), IUSS Pavia, via Ferrata 1, 27100 Pavia, Italy; E-mail: gattanasi@ roseschool.it 
damping characteristics [Song et al., 2006]. These properties, which have led to numerous applications in the biomedical and aerospace industries, have been also evaluated for applications in the area of seismic resistant design and retrofitting [DesRoches and Smith, 2003].

In this work, we focus on the possibility of integrating the SMA application in seismic isolation technology, investigating the potential advantages.

\subsection{Seismic Isolation}

Seismic isolation mitigates the earthquake effects on buildings and their potentially vulnerable contents by modifying the structural global response and improving the performance. This can be obtained by:

- protecting part of the structure assuring its elastic response;

- shifting the main period of vibration to a convenient value that modifies both acceleration and displacement demand;

- increasing the global energy dissipation capacity of the structure thus reducing its displacement demand;

- regularizing the response, modifying the effective relative stiffness, and strength of different parts of the structure.

However, design of isolated structures has some particular concerns. Practical isolation systems must balance between the extent of force isolation and acceptable relative displacements across the isolation system during earthquakes. An extensive and exhaustive description of the topic can be found in Skinner et al. [1993], Naeim and Kelly [1999], Christopoulos and Filiatrault [2006], and Priestley et al. [2007].

\subsection{Shape Memory Alloys}

Shape memory alloys are a novel functional material with increasing applications in many areas, recently also in response control of civil structures [Song et al., 2006]. SMAs have energy dissipation capabilities, large elastic strain capacity, hysteretic damping, good high- and low-cycle fatigue resistance, recentering capabilities, and excellent corrosion resistance [DesRoches and Smith, 2003].

1.2.1. Shape Memory and Superelastic Effects. The most important properties showed by the SMA are the shape memory and the superelastic effects. These unique properties are the result of reversible phase transformations of SMAs. There are two crystal structure phases in SMAs: the austenite, stable at high temperature, and the martensite, stable at low temperature.

In its low-temperature phase, if loaded, SMAs exhibit the shape memory effect. When SMAs in martensite are subjected to external stress, they deform through a socalled detwining mechanism up to several percent strains. Unloading results in a residual strain, as shown in Fig. 1. Heating the previously deformed specimen above a determined temperature results in phase transformation, and a recovering of the original shape (removal of the residual strain).

In its high-temperature form, SMAs exhibit a superelastic effect. Originally in austenitic phase, martensite is formed upon loading beyond a certain stress level, resulting in the stress plateau shown in Fig. 2. However, upon unloading, the martensite becomes unstable, resulting in a transformation back to austenite and the recovery of the original, undeformed shape. 


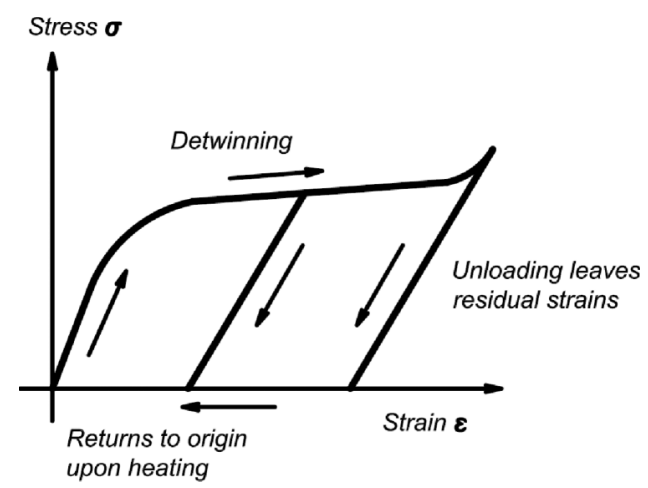

FIGURE 1 Idealized stress-strain curve for shape memory effect.

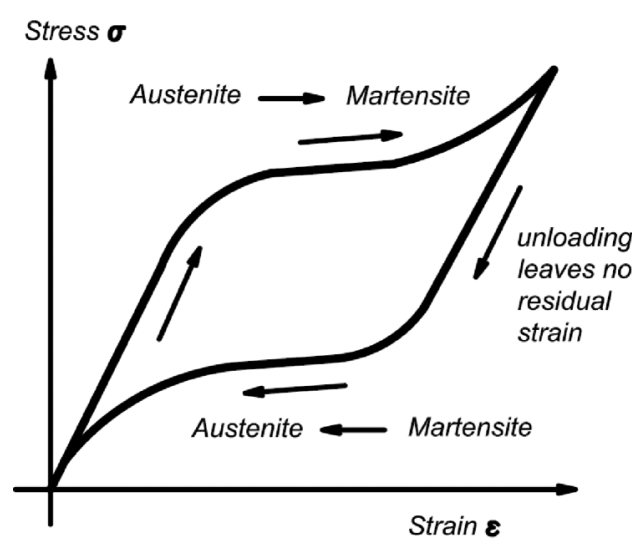

FIGURE 2 Idealized stress-strain curve for superelastic effect.

1.2.2. Temperature Effects. Temperature is the most important factor when predicting the behavior of shape memory alloys. The shape memory process is a thermo-elastic process, meaning that a decrease in temperature is equivalent to an increase in stress. Therefore, as the temperature decreases, a lower stress value is required to induce transformation, as shown in Fig. 3. A specimen tested at low temperature will exhibit the shape memory effect, while the same specimen tested at a high temperature may exhibit the superelastic effect. This can pose significant design issues if the operating temperature of SMAs is not known within a reasonable bound. SMA manufacturing can provide materials quite stable in behavior in the usual design temperature range.

1.2.3. Potentials of SMA in Seismic Engineering Applications. The unique properties of shape memory alloys make them an ideal candidate for use as devices for seismic resistant design and retrofit. Experimental and analytical studies of shape memory alloys show that they are an effective mean of improving the response of buildings and bridges subjected to seismic loading. The re-centering potential of superelastic shape memory alloys is one of the most important characteristic that can be exploited. The ability to undergo cyclical strains greater than $6 \%$ with minimal residual strain (typically less than $1 \%$ ), has been shown to be useful as bracing elements in buildings, and as restraining 


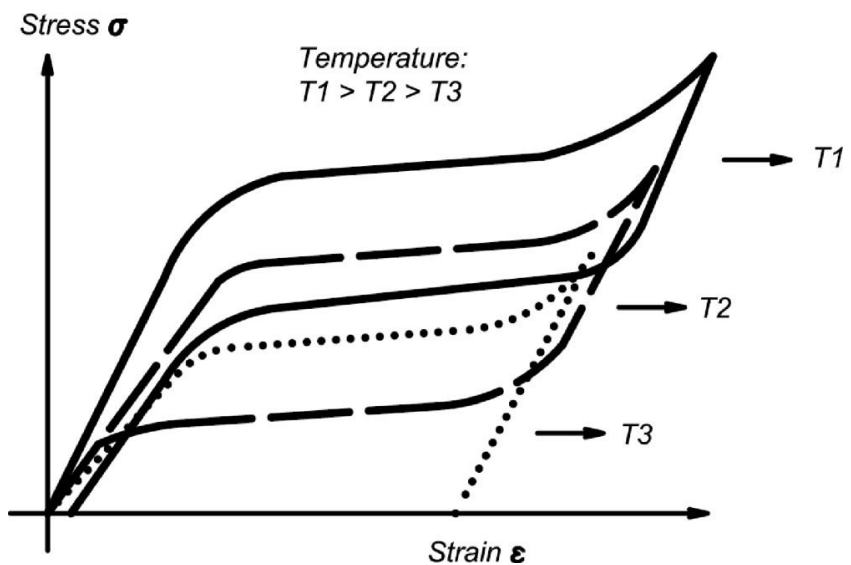

FIGURE 3 Idealized temperature dependent force-displacement response of superelastic NiTi.

elements in bridges. More extensive description of the SMA potentials in civil engineering applications is given in Song et al. [2006] and DesRoches and Smith [2003].

\section{Feasibility of SMA Technology for Seismic Isolation}

We want to investigate the possibility of using shape memory alloys in seismic isolation devices and to evaluate its effectiveness in reaching the structural design goals, compared with traditional isolation devices. In this context, the term shape memory alloys device refers to a bearing systems characterized by a non-linear horizontal force-displacement relation which can be described by a flag-shape hysteresis [DesRoches et al., 2004].

We assume a bearing system providing a horizontal base shear as a function of displacement like the one shown in Fig. 4. This force-displacement relation is given by the superelastic effect of shape memory alloys eventually coupled with other sources of stiffness. The key parameters characterizing the nonlinear behavior of the device (Fig. 4) are:

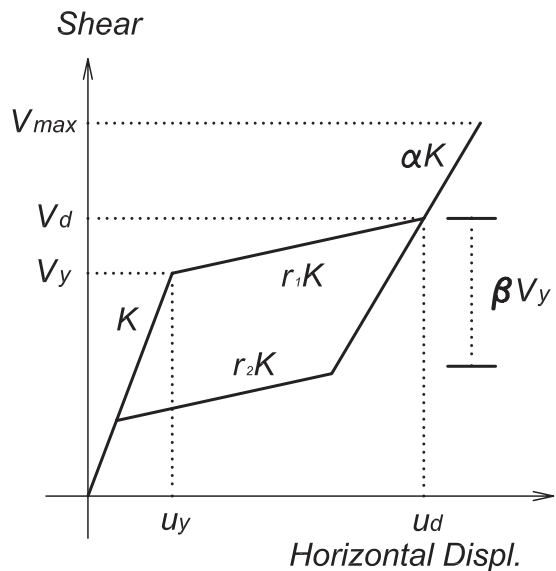

FIGURE 4 Parameters for the SMA superelastic force-displacement model. 
- $K$ : initial lateral stiffness for the system, relative to the first shape memory alloy stiffness contribution and, eventually, to the other stiffness sources;

- $V_{y}$ : lateral force corresponding to the reaching of the device linear limit; it can be interpreted as the shear that produces the initial transformation in the shape memory alloys;

- $u_{y}$ : lateral displacement corresponding to reaching of the linear limit of the forcedisplacement relation for the device;

- $V_{d}$ : lateral force corresponding to reaching of the end of plateau limit; it can be interpreted as the shear at the end of transformation in the shape memory alloys;

- $u_{d}$ : lateral displacement corresponding to reaching of the end of plateau limit;

- $r_{1} K$ : lateral stiffness for the system after reaching the shape memory alloy elastic limit loading, taking also in account, eventually, the other stiffness sources; $r_{1}$ is the fraction of the loading second stiffness respect the first one;

- $\alpha K$ : lateral stiffness for the system after reaching the shape memory alloy second elastic limit at the end of the phase transformation; $\alpha$ is the fraction of the unloading second stiffness respect the initial one;

- $r_{2} K$ : lateral stiffness for the system after reaching the shape memory alloy elastic limit unloading, taking also in account, eventually, the other stiffness sources; $r_{2}$ is the fraction of the unloading second stiffness respect the initial one;

- $\beta V_{y}$ : the lateral force difference between the level of force at which the first transformation (when it is loaded) occurs and the level of force at which the second transformation (when it is unloaded) occurs; $\beta$ is the fraction of the $V_{y}$ lateral force;

- $V_{\text {max }}$ : the maximum lateral force which the device can stand without breaking.

The device we consider behaves in the same way if subjected both to positive and to negative shear, which implies the force-displacement relation is symmetric with respect to the origin between first and third quadrant.

To evaluate the advisability in using a SMA technology in seismic base isolation we assume to be able to design and manufacture a SMA bearing based on the superelastic effect for the horizontal force-displacement relation. At this first stage of work, since we are still investigating the feasibility of the concept, the device has been defined just in terms of the hysteretic relationship, without evaluating the technology able to provide that hysteresis.

\subsection{SMA Technology Isolation Device Design}

To define the main features, underline the drawbacks, and eventually be able to examine the advantages of an isolation system characterized by a lateral force-lateral displacement relation as the one shown in Fig. 4, we compare the response for a system with this hysteresis with an equivalent lead-rubber bearing system (LRB). Obviously, the SMA is characterized by a different force-displacement relation with respect to traditional isolation bearings, but the models have the same yielding and design forces, and the same yielding and design displacements. The concept of equivalence therefore involves that the two different nonlinear hysteresis are characterized by the same initial and second stiffness and the same yielding force and strength. Hence, even effective periods are the same and from a direct-displacement design point of view the only difference between the traditional bearing and the actual isolation device is the hysteretic energy dissipation. 
2.1.1. Reference Lead Rubber Isolator Device. The isolator we consider as a reference is an actual lead rubber bearing, which has been fully characterized experimentally. It is produced by AGOM International srl and the manufacturer provides parameters for the design in terms of elastoplastic hysteresis, listed in Table 1. The force-displacement relation of the model and comparison with experimental test results is shown in Fig. 5. Elastoplastic model is clearly an approximation of the real behavior of the isolator. In particular, the comparison with the experimental results shows that the elastoplastic model does not estimate the initial stiffness or the degradation very well. However, for the representation of the general characteristics of the devices, the adopted model is acceptable, being exact in terms of secant stiffness at the design displacement and giving a good estimation of the hysteretic energy dissipated and of residual displacements. The lead core contribution provides a large and highly dissipating hysteresis, characterized by a hysteretic damping equal to $28 \%$ according to the Jacobsen approach [Jacobsen, $1930 ; 1960]$. The isolator device is compatible with a seismic demand represented by a Eurocode 8 [Eurocode 8, 2003] Type 1 spectra relative to a PGA $=0.25 \mathrm{~g}$ and a soil type $C$.

2.1.2. SMA Isolator Device. We simulate the idealized design of an equivalent SMA isolator considering the properties of the lead rubber bearing in previous subsection. Starting from the elastoplastic model of the actual device as described in Sec. 2.1.1, the flag-shape model uses the same parameters reported in Table 1. With respect to the model

TABLE 1 Nominal design properties of reference lead rubber bearing diameter $500 \mathrm{~mm}$ (courtesy AGOM International srl)

\begin{tabular}{lcl}
\hline & LRB 500 (elastoplastic model) \\
\hline yielding shear & $V_{y}$ & $147 \mathrm{kN}$ \\
design shear & $V_{d}$ & $262 \mathrm{kN}$ \\
yielding displacement & $u_{y}$ & $17.5 \mathrm{~mm}$ \\
design displacement & $u_{d}$ & $162 \mathrm{~mm}$ \\
initial stiffness & $k$ & $8.4 \mathrm{kN} / \mathrm{mm}$ \\
second stiffness & $r k$ & $0.8 \mathrm{kN} / \mathrm{mm}$ \\
secant stiffness & $k_{e}$ & $1.62 \mathrm{kN} / \mathrm{mm}$ \\
seismic vertical load & $W$ & $1653 \mathrm{kN}$ \\
\hline
\end{tabular}

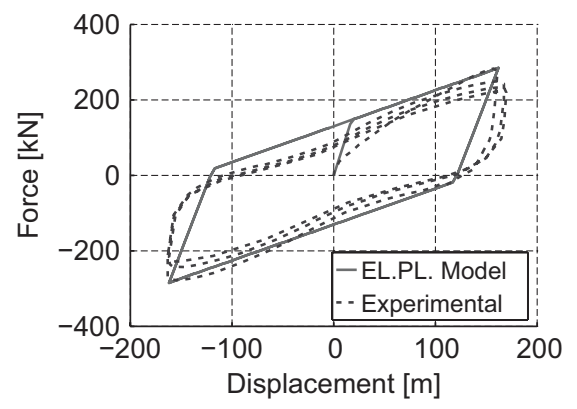

FIGURE 5 LRB 500 force-displacement relations experimental and modeling comparison. 
described in Fig. 4, we consider $r_{1}=r_{2}=r$, so the device has the same stiffness for loading and unloading in the flag-shape plateau, and $\alpha=1$, which means the final stiffness is the same as the initial. Moreover, we assume a large ductility available in the flag-plateau, so that the final hardening occurs far away from the displacement range considered in the design. Finally, the dissipation capabilities of the flag-shape hysteresis are represented by the $\beta$ parameter, measure of the ratio of dissipation.

\subsection{Equivalent Damping Approach Reduction Factor Estimation}

For the design purpose, according to Direct Displacement Based Design (DDBD) approach [Priestley et al., 2007], the structure is modeled with an equivalent single degree of freedom system $(S D O F)$. This is characterized by an equivalent mass $\left(m_{e}\right)$ lumped at an equivalent height $\left(h_{e}\right)$, as shown in Fig. 6, computed to give the SDOF an inertia force equal to the base shear of the original structure, which usually is a multiple degree of freedom $(M D O F)$. The procedure is based on the assumption that a nonlinear system can be represented by an equivalent linear system having a stiffness $k_{e}$ equal to the secant stiffness to the design displacement of the original system, plus an additional damping component, the hysteretic damping, which contributes with the viscous damping to define the equivalent damping $\xi_{e}$. The equivalence concept is shown in Fig. 7, which reproduces the original and the equivalent models for an elasto-plastic hysteresis system. The equivalent damping component $\xi_{e}$ is a measure of the energy dissipated by the structure per cycle and depends on the area of the hysteresis loop together with the elastic

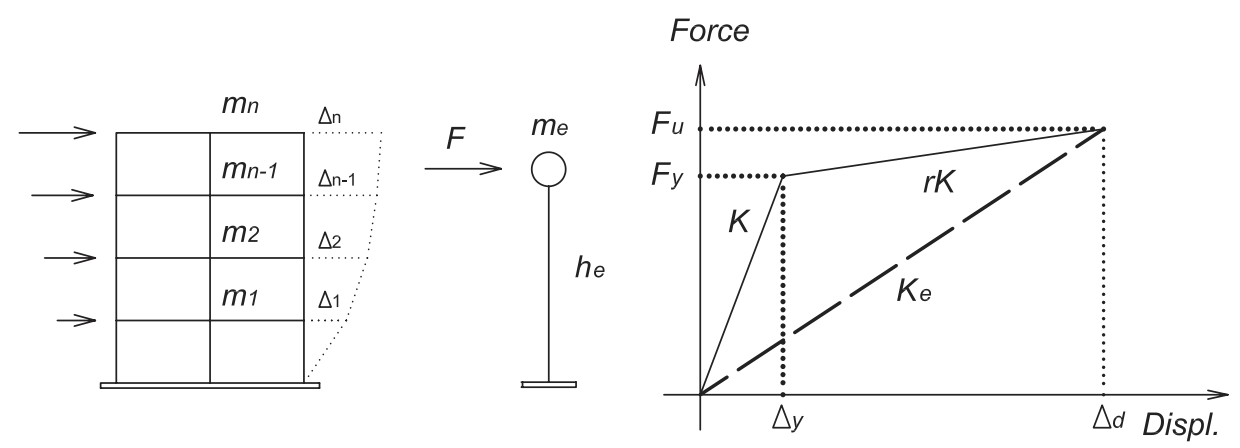

FIGURE 6 MDOF structure-equalvalent SDOF and effective stiffness concept for a billinear force displacement relation envelope.
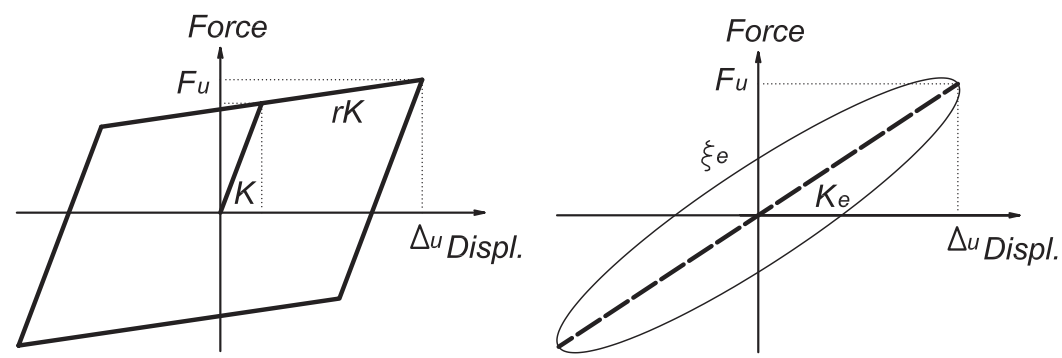

FIGURE 7 Equivalent system concept: original nonlinear system (left) and equivalent linear system with additional damping (right). 
viscous damping, so it is a function of the hysteresis relation shape and of the ductility demand.

Given the previous, damping modeling and estimation is a key point to evaluate the design and the response of the ideal. SMA isolation system and comparison with actual LRB. Moreover, we consider two systems with the same secant stiffness, because the design displacement and shear are the same, and initial and second stiffness are also the same. Therefore, in a displacement based approach the most important difference is given by the damping ratio. The two force-displacement relations are shown in Fig. 8, which for the flag-shaped model the limit case for $\beta=1$ is reported in dotted line. Following a hysteretic area based approach referring to the two models, the first order estimation of the equivalent viscous damping of the system is given by:

$$
\xi_{\text {hyst }}=\frac{2}{\pi} \frac{A_{1}}{A_{2}}
$$

in which $A_{1}$ is the area of the hysteresis skeleton curve and $A_{2}$ is the area of the rectangle enveloping the hysteresis relation [Chopra, 2006], as represented in Fig. 8.

The damping coefficient for the two cases is a function of the displacement ductility, as follows:

- elastoplastic model:

$$
\xi_{\text {hystEP }}=\frac{2}{\pi} \frac{(\mu-1)(1-r)}{\mu(1+r \mu-r)}
$$

- flag-shape model:

$$
\xi_{\text {hystFS }}=\frac{1}{\pi} \frac{\beta(\mu-1)(1-r)}{\mu(1+r \mu-r)} .
$$

From the comparison of expressions (2) and (3), the ratio between the two is a function of $\beta$ if all the other parameters are kept constant. For $\beta=1$, which is the case of the dotted line hysteresis in Fig. 8, the formula (3) gives a damping ratio which is one half of the one given by the (2). This is shown in Fig. 9, which for a constant $r$ value and considering $\beta=1$, the hysteretic damping component is plotted according to the (2) and (3) as a function of displacement ductility $\mu$.

Using the equivalent damping to estimate a reduction coefficient for the design spectra as in Priestley et al. [2007], two formulas are used as a function of the seismic source distance with respect to the site for far field events and for near field events:
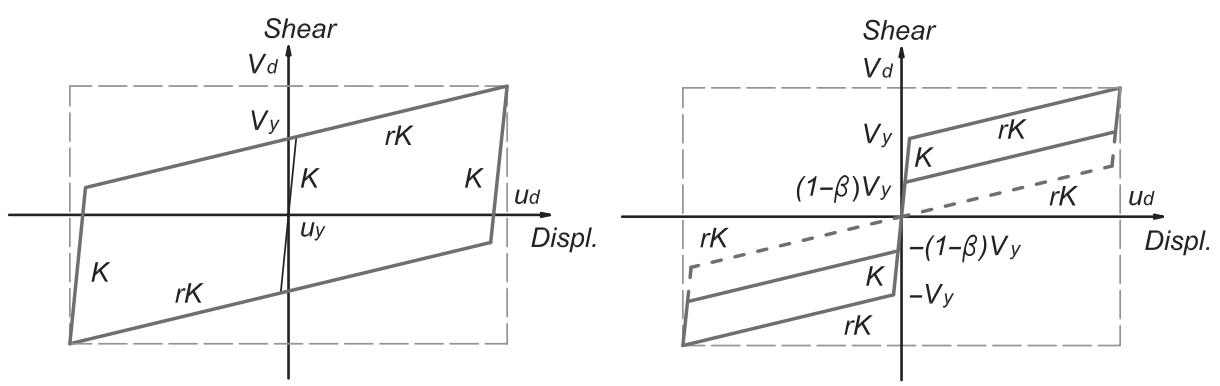

FIGURE 8 Theoretical hysteretic comparison between elastoplastic (LRB, left) and flag-shape (SMA, right) devices. 

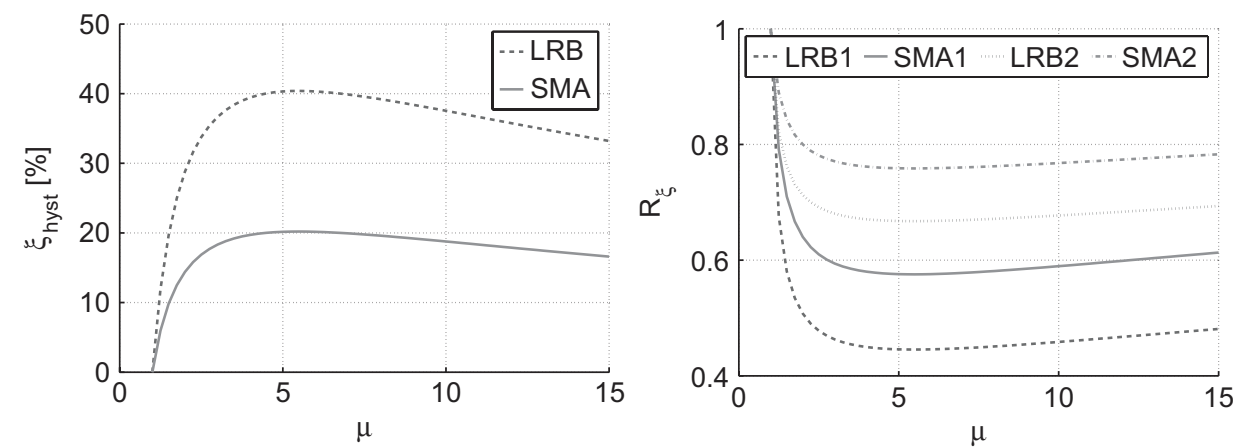

FIGURE 9 Hysteretic damping ratio comparison (left) and equivalent damping reduction factor comparison (the far field values are named (1) while near field are named (2) in the legend) (right) for elastoplastic and flag-shape model considering $\mathrm{r}=5 \%$ and $\beta=1$.

$$
R_{\xi 1}=\left(\frac{10}{5+\xi_{e}}\right)^{0.5} \quad R_{\xi 2}=\left(\frac{10}{5+\xi_{e}}\right)^{0.25}
$$

in which $\xi_{e}$ is given by the viscous elastic and hysteretic damping components:

$$
\xi_{e}=\left(\xi_{v}+\xi_{\text {hyst }}\right) \cdot 100
$$

and assuming $\xi_{v}=5 \%$.

The reduction factor $R_{\xi}$ as a function of ductility $\mu$ is plotted in Fig. 9 again for $\beta=1$ and as a function of displacement ductility $\mu$. Examining the comparison between a flagshape model and an elastoplastic model equivalent damping estimation, SMA response results in a larger displacement demand and in a larger force demand. Hence, if the equivalent damping concept was exact, the flag shaped constitutive relation would significantly reduce the advantages of isolation.

The approach described in this section leads to the conclusion that an isolation device based on a SMA technology and flag-shape hysteresis is always supposed to be less favorable in terms of displacement and force demand if compared with a similar system based on elastoplastic hysteresis. This is because the damping reduction factor is much lower for SMA flag-shape force displacement relation with respect to LRB elastoplastic hysteresis. Even if the flag-shape force displacement relation were characterized by the largest dissipation parameter $\beta$ the SMA reduction factor is one half of the LRB one. For a more reasonable value of $\beta=0.5$, the SMA reduction factor is one fourth on the LRB one.

Some research has been performed looking at the problem of estimating the peak response considering the viscous damping computation together with the secant stiffness concluding that the estimation is not very accurate. Christopoulos et al. [2002] investigated the response of SDOF flag-shaped recentering systems. A new expression for hysteretic damping evaluation in flag-shaped hysteresis has been proposed in the work of Priestley et al. [2005], Blandon et al. [2005] and Grant et al. [2005], even if only for a specific dissipation case and for low ductility level. However, the previous results have been computed using numerical regression, so they are not applicable for our research which has to consider variable dissipation capability and larger ductility level. 
The conclusion that a SMA technology isolation device is not suitable based on the approximate computation of the reduction factor may not be valid.

\subsection{Seismic Response Evaluation of Isolation Devices}

To investigate the response of a shape memory alloy isolator device in more depth and the compare it with the response of an equivalent classical lead rubber bearing, a series of time history analyses are performed. Direct computation of the response and evaluation of envelopes is considered the best way to evaluate the accuracy of the equivalent damping reduction factor approach for a large ductility flag-shape force displacement relation.

2.3.1. Force-Displacement Models for the Isolators. The displacement based design procedure models the structure considering an equivalent linear system characterized by the secant stiffness. If we assume that the design has been performed correctly and all the nonlinear phenomena take place in the isolation level, we focus on its contribution to the overall structural response [Priestley et al., 2007].

To model the isolation device a first option is to use a linear elastic stiffness to the design point, while a more detailed model is to use the real nonlinear hysteresis of the device. In this study case both the actual LRB elastoplastic and the SMA flag-shaped models are characterized by the same secant stiffness, because of the assumptions of Sec. 2.1.2.

The response in terms of shear and displacement demands of the nonlinear systems is supposed to be smaller than the ones of the equivalent linear secant system because of the contribution of the hysteretic dissipation. In concept, the hysteretic damping contribution should be representative of this dissipation and the ratio between the linear and the nonlinear system demands is supposed to be estimated considering the reduction factor $R_{\xi}$. To evaluate this assumption time history analyses considering three models for the isolator devices are performed:

- Elasto-plastic model (Fig. 10, left). The elastoplastic model is representative of the actual lead rubber bearing device.

- Flag-shape model (Fig. 10, center). The flag-shape model reproduces the shearhorizontal displacement relation of the shape memory alloy device. We target a device that performs like the real LRB system in the sense of equivalent shear and displacement capacity and initial and second stiffness.

- Linear elastic model (Fig. 10, right). Given the design displacement $u_{d}$ and the design shear $V_{d}$, which are the same for the previous models, we carry out the analysis of the equivalent linear system, considering a secant stiffness.

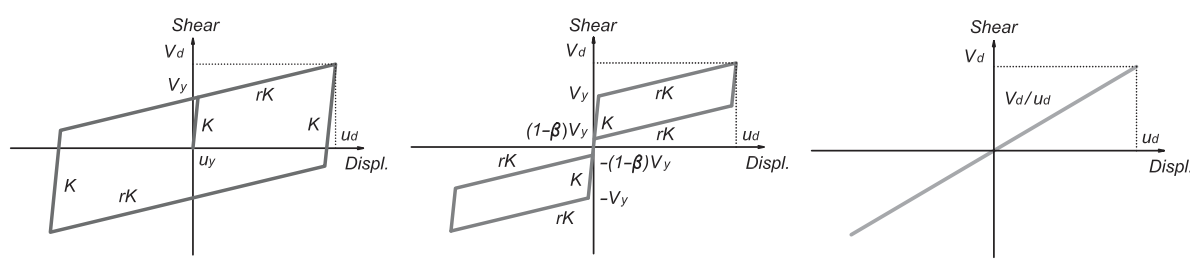

FIGURE 10 Base shear horizontal displacement models for the isolation device response comparison. 
Regarding the elastic damping component in the nonlinear elements, a constant damping proportional to the initial stiffness is used to have the same energy dissipation in the three models if the velocity history were the same. This simplified approach, based on a constant damping coefficient and not on one which changes with the tangent stiffness, has been adopted because the difference in results has been checked to be negligible. In fact, to evaluate the hysteretic dissipation the elastic damping dissipation should be considered constant:

$$
c=2 \xi_{S E C} \sqrt{k_{e} \frac{W}{g}}=2 \xi_{N L} \sqrt{k \frac{W}{g}} \Rightarrow \xi_{N L}=\xi_{S E C} \sqrt{\frac{k_{e}}{k}} .
$$

Given that the damping ratio of the linear elastic system is assumed to be $\xi_{S E C}=5 \%$, according to (6) the damping ratio in the nonlinear models the damping coefficient $c$ is $\xi_{N L}=2.2 \%$. This last is used for the elastoplastic and flag-shape models given that the initial stiffness $k$ is the same.

2.3.2. Evaluation of Different Flag-Shape Dissipation Capability Ratios. The flag-shape hysteresis that can be obtained by the SMA superelastic effect (as shown is Fig. 2) usually does not show a dissipation coefficient as large as the largest one $(\beta \simeq 1)$. The superelastic hysteresis is characterized by a maximum dissipation parameter of the order of $\beta \simeq 0.7$, and this is a function of the material, so the value can be smaller. Even if an high dissipation flag shaped hysteresis is supposed to be better, we want to investigate different dissipation coefficient responses, eventually closer to actual shape memory alloys superelastic effect parameters.

For this purpose, more analyses were performed to evaluate the system response if the $\beta$ factor is smaller, including zero hysteretic dissipation as a limiting case [Priestley et al., 1993]. Six cases are considered, $\beta=0.95, \beta=0.75, \beta=0.55, \beta=0.35, \beta=0.15$, and $\beta=0.0$ (nonlinear elastic behavior), as shown in Fig. 11.
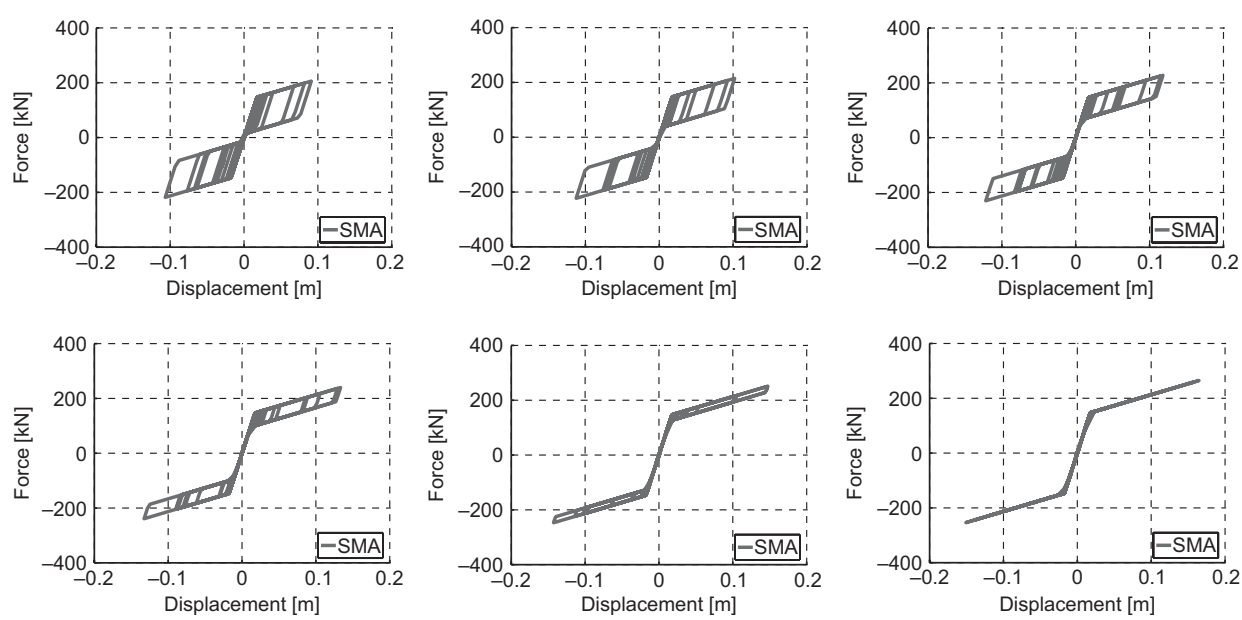

FIGURE 11 Flag-shape hysteresis considering different dissipation parameters $\beta=0.95,0.75,0.55,0.35,0.15,0.0$ used in the analyses (from THA g.m. \#3). 
2.3.3. Ground Motion for the Time History Analyses. Several ground motions are used in the analyses in order to consider the variability of the seismic input. The basic case is the original design spectra for the LRB isolator, which is the Eurocode 8 Type $1 P G A=0.25 \mathrm{~g}$ soil $C$, as reported in Sec. 2.1.1. Given that the effective period of the reference system is about $2 \mathrm{~s}$, the corner period at $2 \mathrm{~s}$ prescribed by the Eurocode 8 is not suitable for the investigation. Hence, remaining consistent with the Eurocode 8 expressions for the spectra computation, the corner period of the design spectra has been extended up to $4 \mathrm{~s}$.

A first set is composed by seven artificial generated ground motions compatible with the design spectra. Those spectra were generated using a research-oriented program [Carr, 2007], considering as a input the design spectra. In addition, recorded but scaled ground motions for seven near fault ground motions were selected from a database [SAC, 1995]. The aim is to evaluate the effects in the hysteretic response of ground motions with velocity pulses. Elastic displacement spectra for the artificial and natural ground motions are shown in Fig. 12 and the pseudo-acceleration spectra are in Fig. 13.

\subsection{Rigid Superstructure Time History Analyses Results}

The design and analysis of an isolated structure can be performed assuming that the superstructure is rigid and therefore the base shear-lateral displacement of the structure is
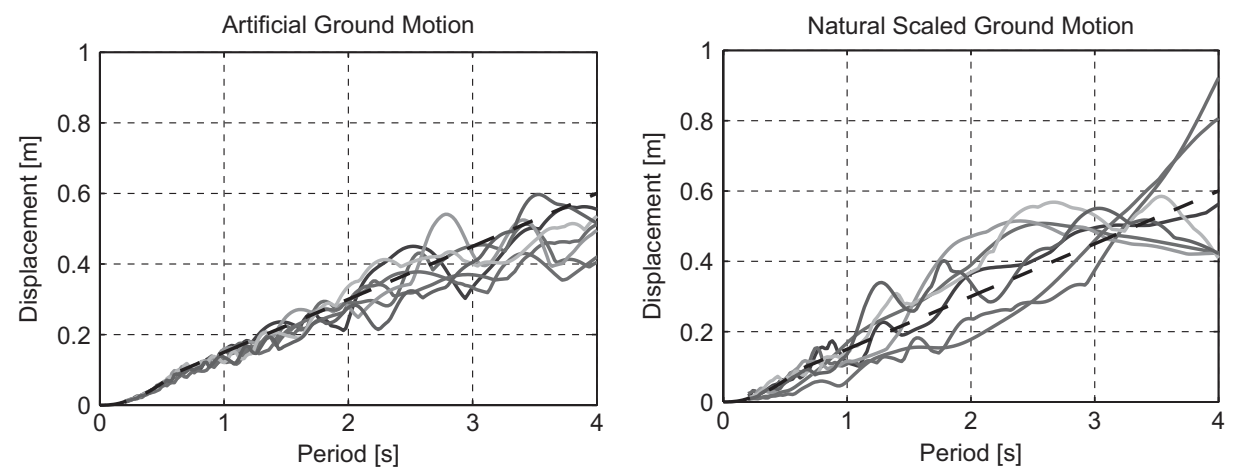

FIGURE 12 Displacement elastic 5\% damping spectra for compatible artificial and near fault ground motions compared with design spectra.
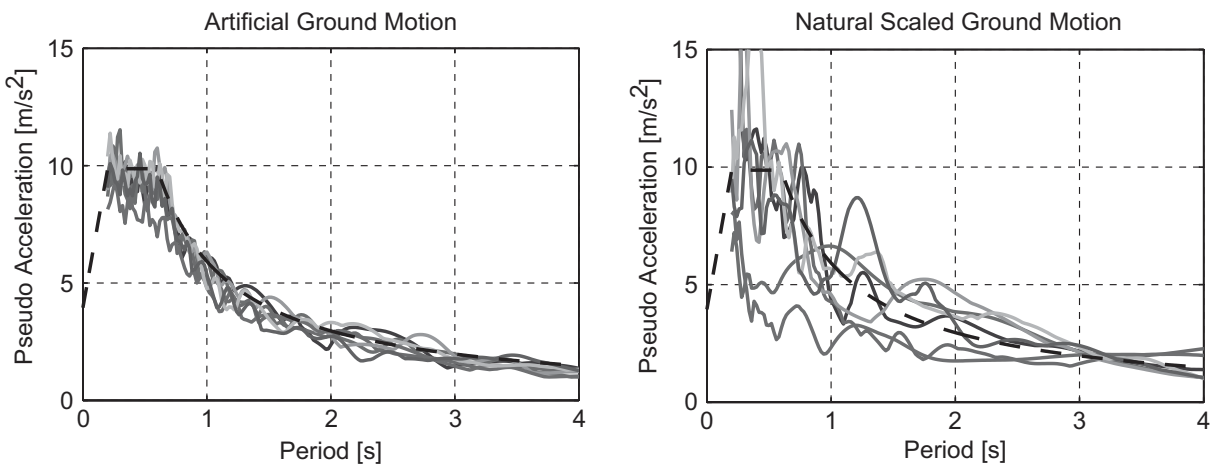

FIGURE 13 Pseudo acceleration elastic 5\% damping spectra for compatible artificial and near fault ground motions compared with design spectra. 

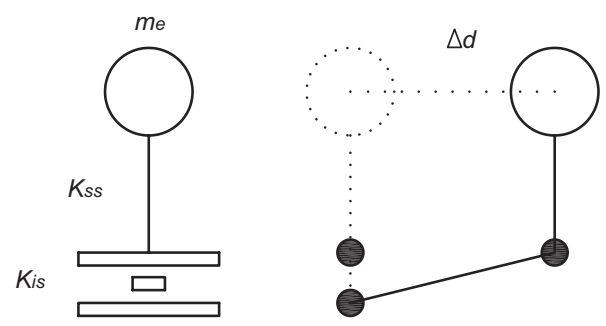

FIGURE 14 Base isolated rigid structure: equivalent displacement profile.
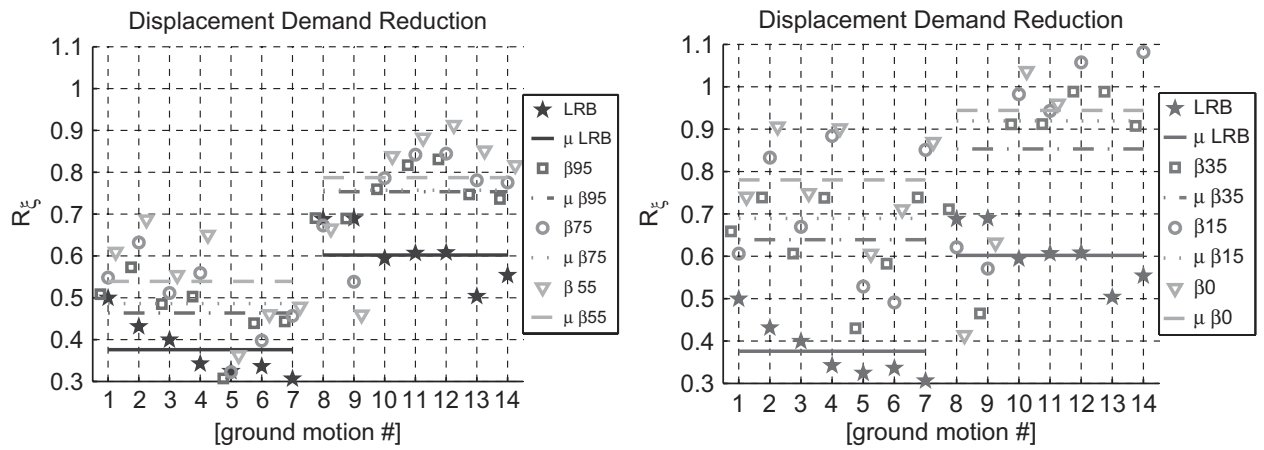

FIGURE 15 Displacement demand values for elastoplastic and different flag-shaped dissipation parameters $\beta(0.95,0.75$, and 0.55 on the left, $0.35,0.15$, and 0.0 on the right $)$ normalized to linear elastic system response for artificial (numbers from 1 to 7 ) and for near fault (numbers from 8 to 14) ground motions.

given by the shear displacement relation of the isolation system. This means that all the displacement occurs only at the isolation level, as shown in Fig. 14. To assess the effects of isolation, the envelopes of displacement and force in the nonlinear system are normalized with respect to the maximum demand in the linear secant system, respectively in Figs. 15 and 16. These ratios are the reduction factors between the linear and nonlinear system due to hysteretic dissipation and the mean values for all the hysteresis considered are shown in Fig. 17. The input energy is expected to change also, therefore the mean value of the input and absorbed energy together with the percentage of input energy dissipated through system absorbed energy is shown in Fig. 19.

The most important conclusion is that differences between the lead rubber bearing elastoplastic model and shape memory alloy flag-shape model are small when compared with the linear elastic displacement and force demand, especially for the medium high flag-shape model dissipation case. Even changing significantly the dissipation factor for a very narrow flag-shape hysteresis does not change the demand quantities as much as would be expected by an area based approach reduction factor computation.

Considering the shear demand comparison in Fig. 16, it is clear that similarities appear to be more important than differences. In terms of displacement demand in Fig. 15, differences of large dissipation capability flag-shape model and elastoplastic model are not large, even if the strong reduction of dissipation increases the system demand, producing in some near fault events a displacement even larger than the one from linear elastic system. 

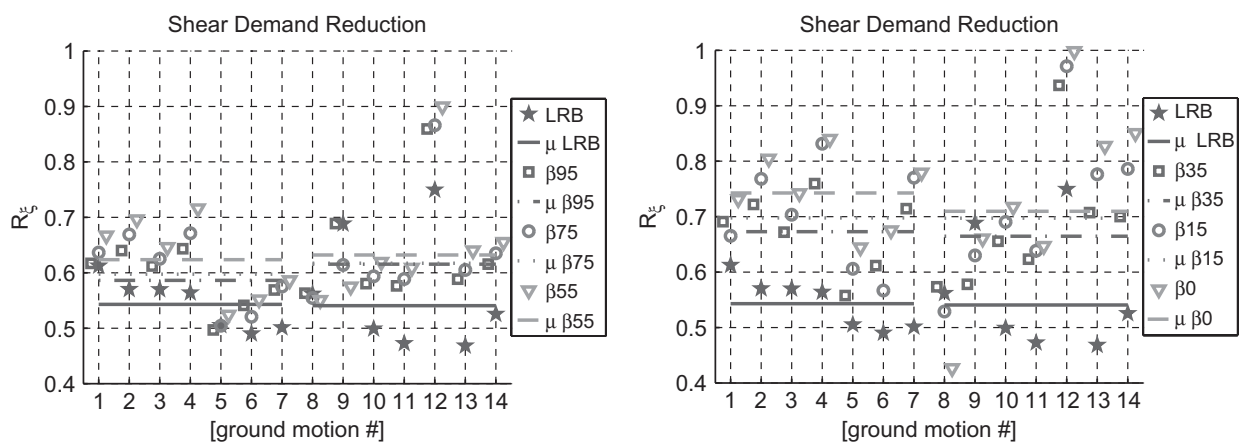

FIGURE 16 Force demand values for elastoplastic and different flag-shaped dissipation parameters $\beta(0.95,0.75$, and 0.55 on the left, $0.35,0.15$, and 0.0 on the right) normalized to linear elastic system response for artificial (numbers from 1 to 7 ) and for near fault (numbers from 8 to 14 ) ground motions.
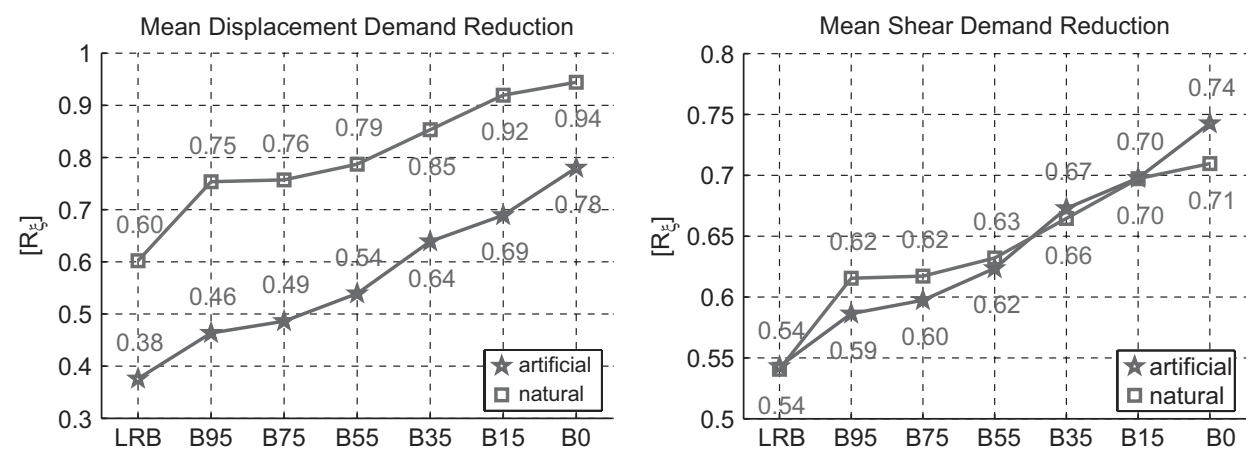

FIGURE 17 Displacement and shear mean reduction factors over the 14 ground motions for the considered hysteresis, listed in the horizontal axis.

An other critical issue for isolation bearings is the residual displacement. This is very undesirable in an isolation system device since it leads to the needing of re-centering of the system after the seismic event. Of course this problem strongly affects an elastoplastic model, especially with a pulse-like near fault seismic input. A major advantage of SMA is the re-centering capability. An example of displacement time history in Fig. 18 shows that lead rubber bearing system is characterized by residuals in all the cases.

Finally, considering the energy absorbed, the elastoplastic model has about the $80 \%$ of the input energy dissipated through the hysteretic relation. In the flag-shape model the percentage is around the $70 \%$ for the large medium dissipation capabilities.

As a general conclusion, the response of an idealized SDOF isolation system based on flag-shape hysteresis considering different dissipations is quite good and comparable to the lead rubber bearing response for a dissipation value in the range $\beta=50 \%$.

\subsection{Flexible Superstructure Time History Analyses Results}

We also perform time history analysis comparisons considering flexible superstructure to investigate the isolation system effectiveness, as shown in Fig. 20. The global design 

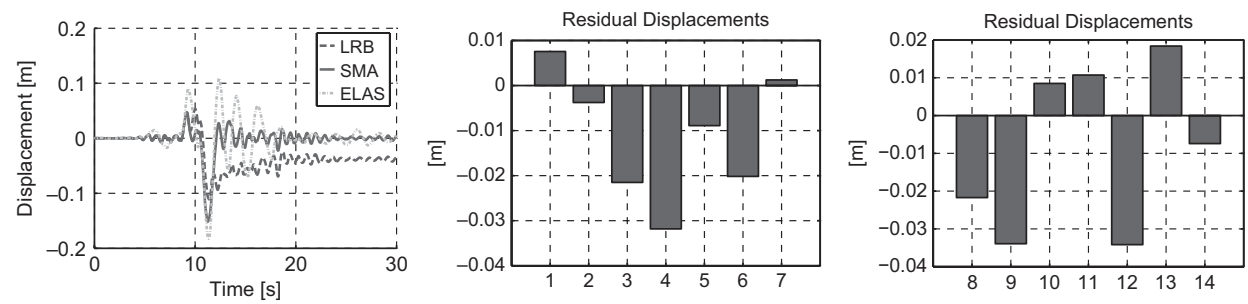

FIGURE 18 Displacement-time response from an analysis of the three systems (left) and LRB model residual displacements in artificial (center) and near-fault (right) ground motion.
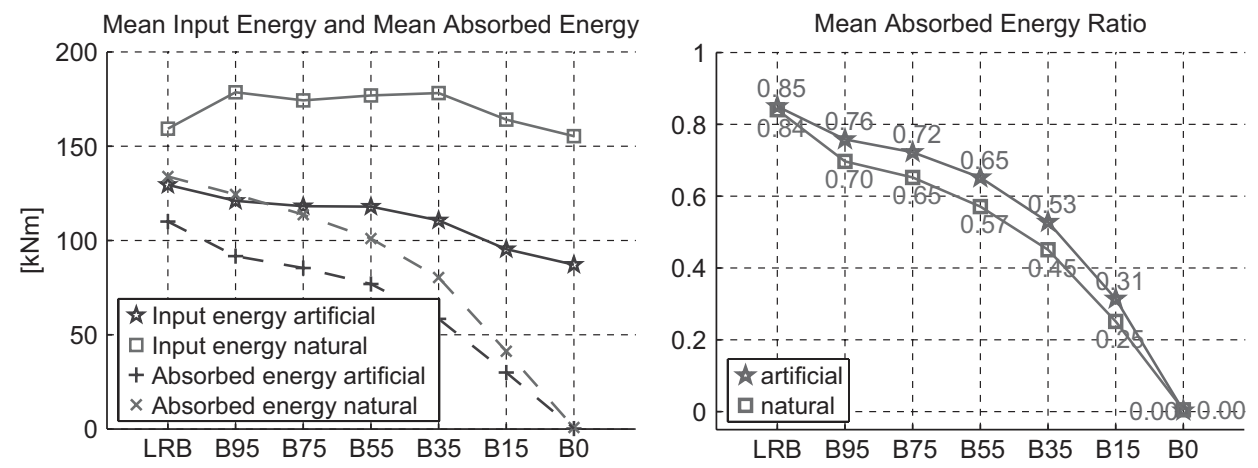

FIGURE 19 Mean input energy showing the amount of input energy absorbed by the systems (left) and ratio between the total input energy and the absorbed one (right) for all the considered hysteresis, listed in the horizontal axis.
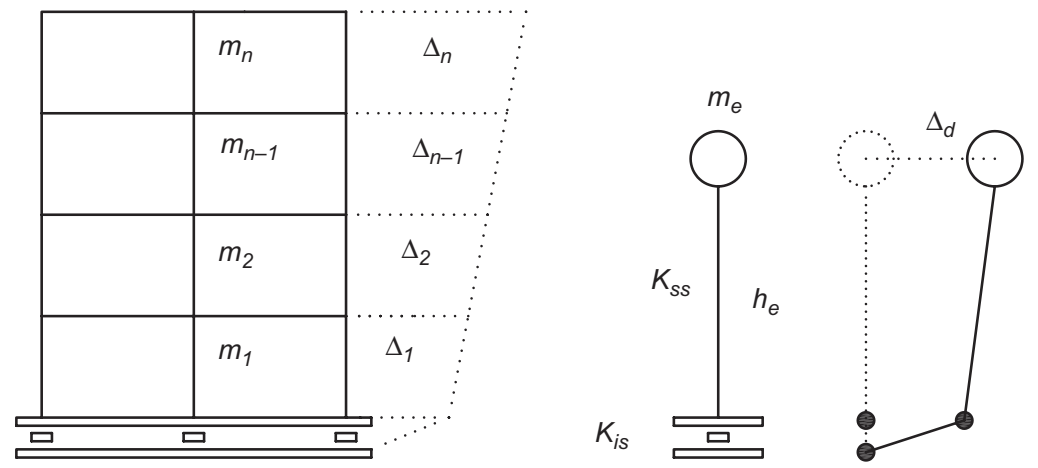

FIGURE 20 Base isolated flexible structure: displacement profile and equivalent SDOF parameters. 
displacement is the sum of the isolation system displacement and of the superstructure displacement:

$$
\Delta_{d, s y s}=\Delta_{d, i s}+\Delta_{d, s s}
$$

Since the superstructure response is supposed to be elastic, displacements of the structural members are not critical. Hence, $\Delta_{d, i s}>\Delta_{d, s s}$, so even in this case the equivalent linear structural system is mainly given by the contributions of the secant stiffness and of the equivalent damping of the isolators, which govern the design.

2.5.1. Analyzed Structure. We consider a simplified design procedure for a base isolated building to get a structural configuration compatible with the original isolator characteristics. The response of the five-bay, three-story plane frame shown in Fig. 21 is investigated. The isolation system is located at the first level, so the first floor is fixed with the foundations and the first slab is rigid and isolated from the first level of columns and foundations. The design philosophy is to isolate the upper stories, which are supposed to resist the seismic event elastically and to design the first story to resist to the maximum load without plastic damage, assuming rigid foundations. There are two column sections, one for the first story and a second for the upper floors. The beam section is constant in all the levels and it is small to provide the required flexibility to the superstructure. The geometric properties are summarized in Table 2. The isolation system is modeled as a spring element, like in the previous SDOF system analysis. The mass is lumped at the beam-column connections, based on tributary areas of the floors. The non isolated structure has a fundamental mode of vibration period of $1.07 \mathrm{~s}$, and a summary of the non isolated building modal is reported in Table 3. Modeling the isolation system with an equivalent linear secant stiffness using parameters in Table 1, the modal properties are

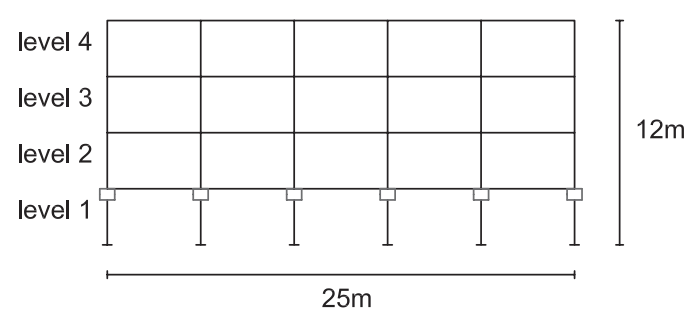

FIGURE 21 Geometric outline of the frame system we are considering for the flexible superstructure approach.

TABLE 2 Frame model geometric properties

\begin{tabular}{|c|c|c|c|c|c|}
\hline \multicolumn{6}{|c|}{ Test frame properties } \\
\hline \multicolumn{3}{|c|}{ Materials } & \multicolumn{3}{|c|}{$1^{\text {st }}$ Level columns } \\
\hline Concrete Elastic Modulus & $E$ & $25000 \mathrm{MPa}$ & Depth & $d_{1 c}$ & $0.80 \mathrm{~m}$ \\
\hline Concrete Poisson Ratio & $v$ & 0.4 & Width & $w_{1 c}$ & $0.80 \mathrm{~m}$ \\
\hline \multicolumn{3}{|c|}{ Beams } & \multicolumn{3}{|c|}{ Upper level columns } \\
\hline Depth & $d_{b}$ & $0.40 \mathrm{~m}$ & Depth & $d_{u c}$ & $0.40 \mathrm{~m}$ \\
\hline Width & $w_{b}$ & $0.25 \mathrm{~m}$ & Width & $w_{u c}$ & $0.30 \mathrm{~m}$ \\
\hline
\end{tabular}


TABLE 3 Modal properties from fixed structure analysis

\begin{tabular}{lcc}
\hline \multicolumn{3}{c}{ Not isolated modal frame properties } \\
\hline Mode number & Vibration period & Participating mass \\
\hline 1 & $1.07 \mathrm{~s}$ & $69 \%$ \\
2 & $0.33 \mathrm{~s}$ & $10 \%$ \\
3 & $0.18 \mathrm{~s}$ & $3 \%$ \\
4 & $0.09 \mathrm{~s}$ & $16 \%$ \\
\hline
\end{tabular}

TABLE 4 Modal properties from isolated structure analysis

\begin{tabular}{lcc}
\hline \multicolumn{3}{c}{ Isolated Modal Frame Properties } \\
\hline Mode Number & Vibration Period & Participating Mass \\
\hline 1 & $2.14 \mathrm{~s}$ & $98.3 \%$ \\
2 & $0.58 \mathrm{~s}$ & $1.6 \%$ \\
\hline
\end{tabular}

reported in Table 4. The fundamental period elongation from the non isolated to the isolated case is about the $100 \%$, so the superstructure flexibility has to be taken into account, as suggested in Priestley et al. [2007].

Before conducting the time history analyses, the system force-deformation behavior is investigated through a pushover analysis. The applied load pattern is constant with the height of the building to represent the first mode of vibration of the isolated structure. The system capacity curve, governed by the isolation properties, is the same for both the lead rubber and the shape memory alloy isolation bearings. The base shear and the first-level displacement relationship account for the behavior of the isolation system alone. Comparing the base shear with the roof level displacement curve, we investigate the flexibility of the superstructure. The results of pushover analysis and comparison are shown in Fig. 22.

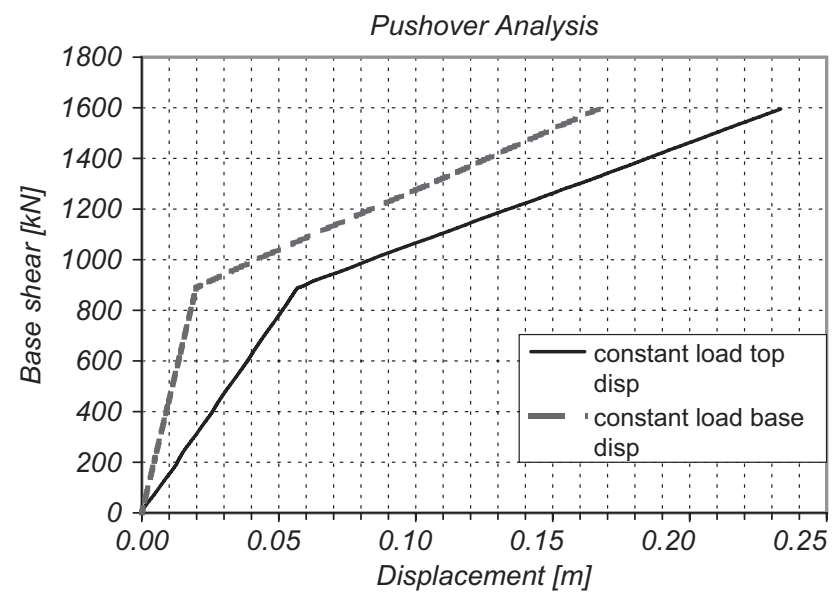

FIGURE 22 Capacity curve from pushover analysis of the structure; an uniform lateral load has been considered and two displacement control points have been taken into account, one at the top of the first level and one at the roof level of the superstructure. 
2.5.2. System Modeling Issues. The time history analyses uses the same ground motions we used previously and the same force-displacement relations for the isolators. An important issue in this context is the global structural damping evaluation. We want to take into account explicitly in the equation of motion only the viscous component of the isolation devices. The model in this case is more complex with respect to the SDOF because of the isolation system and superstructure contributions. The superstructure is assumed to have a $5 \%$ equivalent viscous damping in all vibration modes.

To compare the results, we want to take into account the same damping contribution in all the isolated structural models referring to the system secant stiffness to the design displacement. Given the initial stiffness of the nonlinear models, a 5\% ratio of the secant stiffness is equivalent to $2.2 \%$ based on the initial stiffness of the isolation device. The isolator damping ratio to be combined with the super structure damping, which is done using a weighted sum of the flexibility sources in the structural first mode, leads to:

$$
\begin{aligned}
& \xi_{e, s y s}=\frac{\xi_{e, i s} \Delta_{d, i s}+\xi_{e, s s} \Delta_{d, s s}}{\Delta_{d, i s}+\Delta_{d, s s}}= \\
& =\frac{\xi_{e, \text { is }} D_{\max \text { base }}+\xi_{e, s s} D_{\max s s}}{D_{\max t o p}}= \\
& =\frac{2.2 \cdot 0.167+5 \cdot 0.066}{0.233}=3
\end{aligned}
$$

in which $\Delta_{d}$, is and $\Delta_{d, \text { ss }}$ are, respectively, the design displacement of the isolation system and of the superstructure. They are approximated as $D_{\max }$ base and $D_{\max s s}$, which are the contribution of the total displacement given by the isolation system and by the superstructure computed from the pushover analysis at the design total displacement. The damping ratios, $\xi_{e, \text { is }}$ and $\xi_{e, s s}$, are, respectively, the damping coefficient of the isolation system and of the superstructure. According to (8), system viscous damping for the first mode is the $3 \%$ of the critical one, still computed using the initial stiffness. Hence, we perform analyses of lead rubber bearing frame isolated system and of shape memory alloys device frame isolated system considering the value $\xi_{e, s y s}=3 \%$ in the fundamental mode.

2.5.3. Evaluation of Results considering different SMA Dissipation Capabilities. To investigate response of flexible superstructure system, the response is reported in term of floor shear, floor displacement, and acceleration demand.

- Displacements.

The first comparison concerns displacements at different floor levels as shown in Fig. 23. The test results confirm that the displacement demand is larger in equivalent secant stiffness linear elastic system than in nonlinear hysteresis models. The reduction takes into account of the hysteretic dissipation with respect the secant linear model is larger for artificial ground motion, but it is important for near fault events too. The displacement reduction factor increases with the increase of the floor level number. Concerning the elastoplastic and flag-shape model comparison, responses are not very different for the higher range of SMA dissipation parameters. Large dissipating flag shaped hysteresis models performs better than the less dissipating ones, but if the flagshape dissipation factor $\beta$ is at least about $\beta \simeq 50 \%$, the maximum displacement demand in flag-shape model is similar to the one of lead rubber bearing isolation device. 

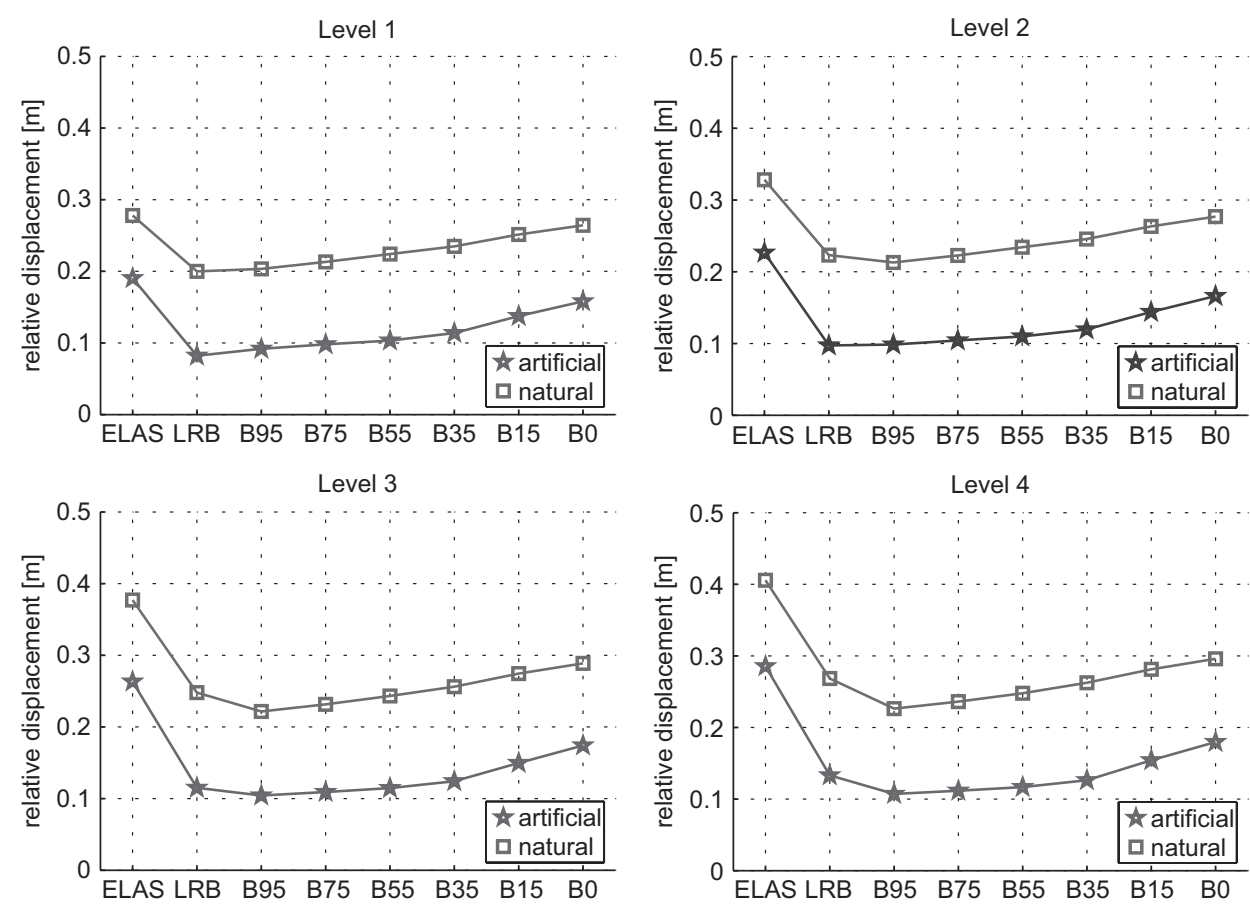

FIGURE 23 Maximum relative displacement demand mean values from artificial and near fault ground motions at different levels.

- Accelerations.

Seismic isolation reduces the acceleration at the floor levels compared the nonisolated structure. The nonlinear hysteresis models produces larger mean accelerations than the linear elastic secant stiffness model. However, the flag shape models for a range of $\beta>50 \%$ is more favorable in terms of floor acceleration than elastoplastic model at every level, as shown in Fig. 24.

- Shear forces.

The mean values of story shear force are not very different considering the linear, the elastoplastic and the flag-shape models, as shown in Fig. 25. While the linear model response values are characterized by a decrease of story shear demand with increasing elevation in the building, in the nonlinear cases also decreases with elevation but not as much. The differences between flag-shape and elastoplastic model are quite small and also the differences in decreasing the SMA dissipation are small. Flag-shape hysteresis perform well for a large range of $\beta$ values, at least larger than $\beta=50 \%$, for which the floor shear is very similar or smaller than in the case of the elasto-plastic model.

\section{Conclusions}

An investigation about the feasibility of shape memory alloy technology application to seismic isolation devices has been performed. Nonlinear time history analysis results were considered to study the problem. The behavior of a model representing a conventional lead rubber bearing device was compared with the behavior of a hypothetical shape memory alloy device and with an equivalent linear elastic model. They were 

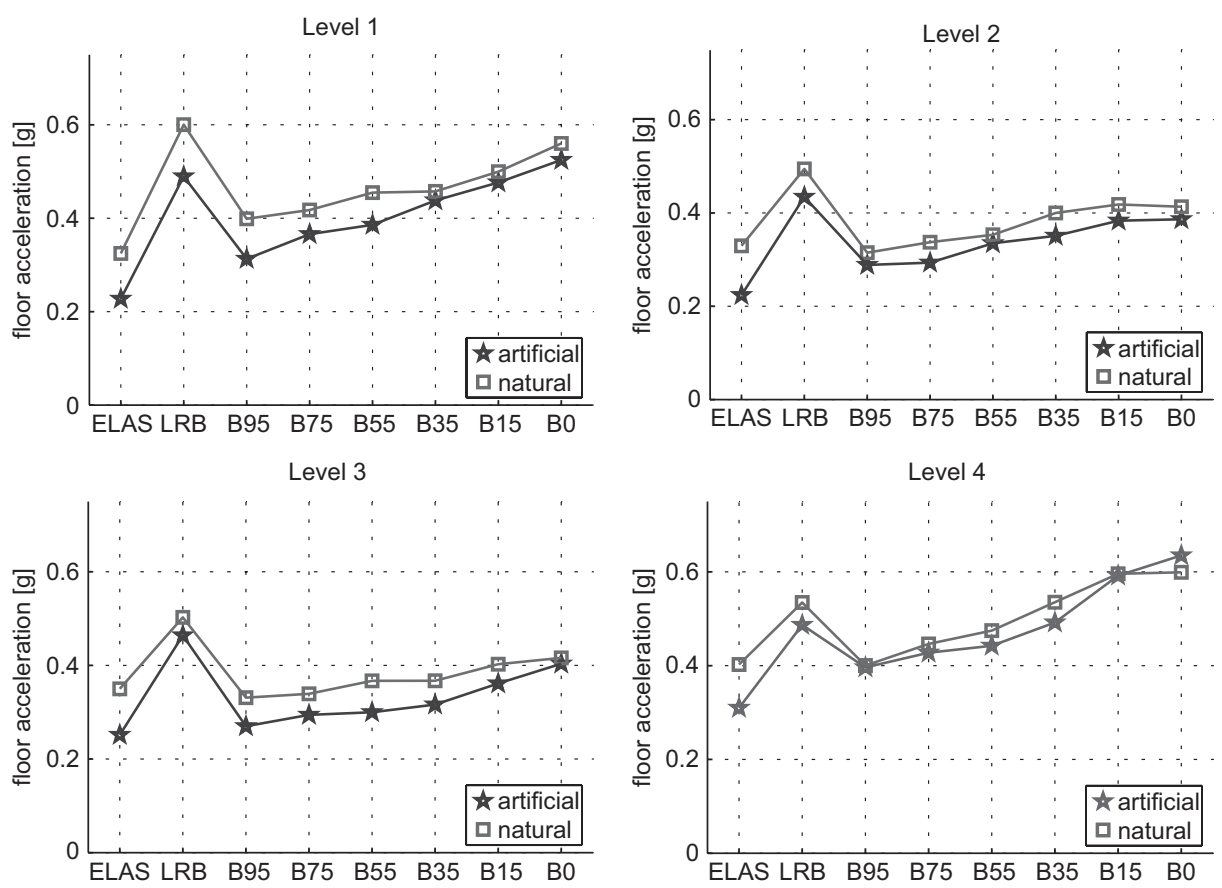

FIGURE 24 Maximum total acceleration demand mean values from artificial and near fault ground motions at different levels.
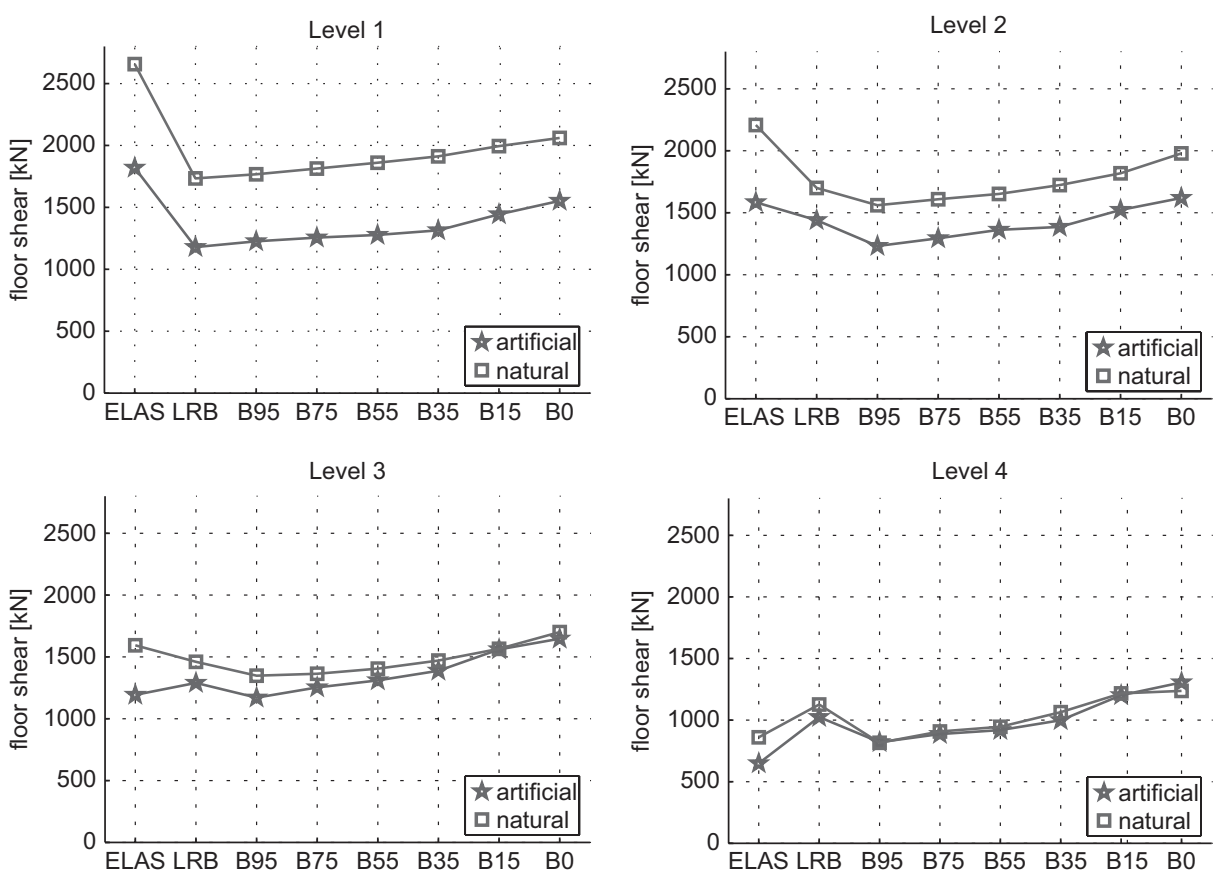

FIGURE 25 Maximum shear demand mean values from artificial and near fault ground motions at different levels. 
characterized by the same secant stiffness and strength with respect to the LRB device but different hysteresis.

The reduction factor of displacements and forces based on the hysteresis area estimation would indicate that the flag-shape hysteresis is more demanding than the elastoplastic model. Time history analyses demonstrates that differences are present, but they are not as large as indicated using the hysteretic area based approach. Considering either the single degree of freedom and the multiple degree of freedom analyses, displacement and force demand of a shape memory alloy device and of a lead rubber bearing system are similiar, regardless the big differences in hysteretic area. Analogous results are found considering an energy approach, because the absorbed energy from the time history analyses is close in elastoplastic and flag-shape models. We verified that these conclusions are valid not only for the more dissipating flag-shaped model, but also for smaller dissipation flag-shape hysteresis provided that the beta parameter is at least in the order of $\beta \simeq 50 \%$. In practice, this mean that even if the dissipation parameter is the one of the shape memory alloy not prestressed, results are still quite good. Shape memory alloy based technology system has zero residual displacement. This is an important advantage for damage mitigation in structural seismic design if compared with the lead rubber bearing systems with elastoplastic model.

Given these results, the conclusion of this investigation is that the SMA application in seismic isolation is possible and can lead to several advantages. A SMA device used as a lateral restrain element for a bearing system would provide recentering properties together with good energy dissipation capability.

After this preliminary investigation, the main effort has to be in the design of a real technology to get a lateral force base shear like, or similar to, the flag-shaped model considered in this work. Many issues have to be considered, in particular the difficulty of providing a large displacement capacity from a SMA manufactured element and to design a multi-directional bearing.

\section{References}

Attanasi, G. [2008] "Feasibility Assessment of Innovative Isolation Bearing System with Shape Memory Alloys," MSc Dissertation, European School for Advanced Studies in Reduction of Seismic Risk (ROSE School), IUSS, Pavia.

Blandon, C. A. and Priestley, M. J. N. [2005] "Equivalent viscous damping equations for direct displacement based design," Journal of Earthquake Engineering 9, 257-278.

Carr, A. J. [2007] Ruaumoko Manual: User Guide to Associated Programs, Departement of Civil Engineering, University of Canterbury, ChristChurch, New Zealand.

Chopra, A. K. [2006] Dynamics of Structures. Theory and Applications to Earthquake Engineering, Third Edition, Prentice-Hall, Upper Saddle River, NJ.

Christopoulos, C., Filiatrault, A., and Folz, B. [2002] "Seismic response of self-centering hysteretic SDOF systems," Earthquake Engineering and Structural Dynamics 31(5), 1131-1150.

Christopoulos, C. and Filiatrault, A. [2006] Principles of Passive Supplemental Damping and Seismic Isolation, IUSS Press, Pavia.

Clough, R. W. and Penzien, J. [1993] Dynamics of Structures, McGraw-Hill, New York.

DesRoches, R. and Smith, B. [2003] "Shape memory alloys in seismic resistant design and retrofit: a critical review of their potential and limitations," Journal of Earthquake Engineering 7, 1-15.

DesRoches, R., McCormick, J., and Delemont, M. [2004] "Cyclic properties of superelastic shape memory alloy wires and bars," ASCE Journal of Structural Engineering 130(1), 38-46.

Eurocode 8 [2003] "Design of structures for earthquake resistance, part i: General rules, seismic actions and rules for buildings," pre-ENV 1998-1, CEN, Brussels. 
Grant, D. N., Blandon, C. A., and Priestley M. J. N. [2005] Modelling Inelastic Response in Direct Displacement Based Design, IUSS Press, Pavia.

Iwan, W. and Gates, N. [1979] "Estimating earthquake response of simple hysteretic structures," Journal of Engineering Mechanics Division 105, 391-405.

Jacobsen, L. S. [1930] "Steady forced vibrations as influenced by damping," ASME Transactions 52, 169181.

Jacobsen, L. S. [1960] "Damping on composite structures" Proceedings of the II World Conference of Earthquake Engineering, Tokyo and Kyoto, Japan, pp. 1029-1044.

Naeim, F. and Kelly, J. M. [1999] Design of Seismic Isolated Structures. From Theory to Practice, John Wiley and Sons, New York, NY.

Priestley, M. J. N., Calvi, G. M., and Kowalsky, M. J. [2007] Displacement-Based Seismic Design of Structures, IUSS Press, Pavia.

Priestley, M. J. N. and Grant, D. N. [2005] "Viscous Damping in seismic design and analysis," Journal of Earthquake Engineering 9, 229-255.

Priestley, M. J. N. and Tao, J. R. T. [1993] "Seismic response of precast-prestressed concrete frames with partially debonded tendons," PCI Journal 38, 58-69.

Skinner, R. I., Robinson, W. H., and McVerry, G. H. [1993] An Introduction to Seismic Isolation, John Wiley and Sons, Chichester, UK.

Song, G., Ma, N., and Li, H.-N. [2006] "Applications of shape memory alloys in civil structures," Engineering Structures 28, 1266-1274. 